\title{
Communication
}

\section{Safety Study on Ketoprofen in Pigs: Evaluating the Effects of Different Dosing and Treatment Scheme on Hematological, Hepatic, and Renal Parameters}

\author{
Luis Emilio Fazzio 1,*(D), Santiago José Raggio ${ }^{2}$, Juan Facundo Romero ${ }^{3}$, Juver Membrebe ${ }^{4}$ \\ and Antonio Humberto Hamad Minervino ${ }^{5, *}$ (]) \\ 1 Laboratorio de Patología Especial Veterinaria, Veterinary Faculty, La Plata University, Avenue 60 and 118 s/n, \\ La Plata 1900, Argentina \\ 2 Biogenésis Bagó, Panamericana Km 38,5, Garín, Buenos Aires B1619, Argentina; \\ santiago.raggio@biogenesisbago.com \\ 3 Atención Veterinaria Integral Chascomús (AVICh) Ensayos Clínicos Veterinarios, Cinacinas 105, Chascomús, \\ Buenos Aires CP 7130, Argentina; juanfacundoromero@yahoo.com.ar \\ 4 Biogenésis Bagó (Shanghai) Biotechnology Company Limited., 828-838 Zhangyang Road, Huadu Mansion \\ Pudong New District, Shanghai 200122, China; juver.membrebe@biogenesisbago.com \\ 5 Laboratory of Animal Health, LARSANA, Federal University of Western Pará, UFOPA, \\ Santarém 68040-080, Brazil \\ * Correspondence: fazzio@fcv.unlp.edu.ar (L.E.F.); ah.minervino@gmail.com (A.H.H.M.)
}

check for updates

Citation: Fazzio, L.E.; Raggio, S.J.; Romero, J.F.; Membrebe, J.;

Minervino, A.H.H. Safety Study on Ketoprofen in Pigs: Evaluating the Effects of Different Dosing and Treatment Scheme on Hematological, Hepatic, and Renal Parameters. Vet Sci. 2021, 8, 30. https://doi.org/ $10.3390 /$ vetsci 8020030

Academic Editors: Dominiek Maes and Hanchun Yang

Received: 8 December 2020

Accepted: 14 February 2021

Published: 18 February 2021

Publisher's Note: MDPI stays neutral with regard to jurisdictional claims in published maps and institutional affiliations.

Copyright: (C) 2021 by the authors Licensee MDPI, Basel, Switzerland. This article is an open access article distributed under the terms and conditions of the Creative Commons Attribution (CC BY) license (https:// creativecommons.org/licenses/by/ $4.0 /)$.

\begin{abstract}
A safety study on ketoprofen $10 \%$ was carried out on pigs using a different dosing and treatment scheme. Forty healthy crossbreed pigs with similar age, weight, and body condition score were distributed into five treatment groups. The pigs were intramuscularly injected once with different doses of ketoprofen: $3 \mathrm{mg} / \mathrm{kg}$ (group 1X), $6 \mathrm{mg} / \mathrm{kg}$ (group 2X), $9 \mathrm{mg} / \mathrm{kg}$ (group 3X). In addition, the $3 \mathrm{mg} / \mathrm{kg}$ dosis was administered on three consecutive days (group 1X ext.). Intramuscular injections of saline solution were used in control group (CTL). The pigs were clinically examined throughout the trial and blood samples were taken for hematological and biochemical evaluation on days -4 (before treatment) $,+3,+7$, and +14 (the end of the trial). Any unusual behaviour or clinical signs were reported as potential toxic effects of ketoprofen. Serum measurements showed that none of the ketoprofen doses produced changes in renal or hepatic biochemical parameters, liver enzymes, or total bilirubin. Likewise, hematological assessment indicated no altered parameters or hematocrit percentage in the study groups. These results demonstrate that ketoprofen has no adverse effects in pigs when the doses and scheme evaluated in this study are applied.
\end{abstract}

Keywords: non-steroidal anti-inflammatory drug; intramuscular treatment; safety; swine

\section{Introduction}

Ketoprofen is a non-steroidal anti-inflammatory drug (NSAID) that derives from propionic acid [1]. These drugs act through the non-selective inhibition of the two cyclooxygenase isoforms (COX1 and COX2). Cyclooxygensase-1 produces toxic effects, such as altered gastrointestinal function, hepatopathies, nephrotoxicity, and coagulation disorders [2,3]. In contrast, COX2 inhibition exerts NSAID therapeutic effects [4-6].

Ketoprofen is a chiral compound that contains one asymmetric carbon atom and thus exists in two enantiomeric forms ( $R$ and $S$ ketoprofen) [2,7] which are detected in plasma after intramuscular injections $[3,8,9]$. Ketoprofen is then inactivated in the liver through hydrolysis and glucuronic acid conjugation [10].

In veterinary medicine, ketoprofen is used as an antipyretic, anti-inflammatory, and analgesic agent [3,11-14]. A dose of $3 \mathrm{mg} / \mathrm{kg}$ reduced mortality rates in pre-weaning piglets [15], improved body conditions of postpartum sows [16], was effective in treating 
sows with lameness [3] and reduced body temperature in pigs challenged with Actinobacillus pleuropneumoniae [11], but was ineffective at alleviating surgical castration pain in piglets [17].

Although there are several studies on ketoprofen in many other species, published data on pigs are scarce [5]. Its potential adverse effects on the indicators of kidney damage (urea and creatinine), liver enzyme function (alkaline phosphatase, aspartate aminotransferase, gamma glutamyl transpeptidase, total bilirubin), and hematological parameters (erythrocytes, leukocytes, platelets) have not been evaluated when using different doses and treatment schemes. The aim of this work was to evaluate the impact of ketoprofen on hematological, hepatic and renal parameters using a different dosing and treatment scheme in pigs.

\section{Materials and Methods}

All the experimental procedures were approved by the Institutional Animal Care and Use Committee (CICUAL, for its Spanish acronym), Faculty of Veterinary Sciences, National University of La Plata, Argentina (Protocol No 107-1-20P).

This trial was performed on a commercial farm located in the district of Castelli, Buenos Aires Province, Argentina (-36.176225, -57.762943). The farm has a capacity for 250 sows on a single site positive for enzootic pneumonia/swine influenza and negative for PRRS. The pigs were managed as per usual practice on the farm. Forty crossbreed pigs (Duroc Jersey $x$ Landrace $x$ Yorkshire) of both sexes were selected (17 males; 23 females). They were clinically healthy and had similar age (60 \pm 3 days), body weight $(22.4 \pm 3.2 \mathrm{~kg})$, and body condition score 4 (1-5 scale). All the animals were identified with a tag in the left ear. Weight and body condition scores were individually evaluated before ketoprofen administration (day -4 of the trial). The selected pigs were grouped according to their sex and weight and then randomly distributed into five treatment groups: group $1 \mathrm{X}(3 \mathrm{mg} / \mathrm{kg}$ ketoprofen, $1 \mathrm{~mL} / 33 \mathrm{~kg}$ BW; Ketoprofeno Biogénesis Bagó ${ }^{\circledR}$, Biogénesis Bagó, Buenos Aires, Argentina); group 2X (6 mg/kg ketoprofen, $2 \mathrm{~mL} / 33 \mathrm{~kg} \mathrm{BW})$; group 3X (9 mg/kg ketoprofen, $3 \mathrm{~mL} / 33 \mathrm{~kg}$ BW), group $1 X$ ext. (extended, $3 \mathrm{mg} / \mathrm{kg}$ ketoprofen, $1 \mathrm{~mL} / 33 \mathrm{~kg}$ BW administered on 3 consecutive days within a $24 \mathrm{~h}$ interval) and CTL group (sterile saline solution, $1 \mathrm{~mL} / 33 \mathrm{~kg}$ BW). The ketoprofen and saline solution were administered via intramuscular route. Day 0 corresponded to ketoprofen or sterile saline solution treatment day for $1 X, 2 X, 3 X$ and CTL groups. In 1X ext. group, the first, second and third dose was given on day -2 , day -1 and day 0 , respectively. All pigs were examined daily throughout the trial (from day -4 to day +14 ). Behavior, manifestation, of pain and local inflammation at the injection site were also evaluated.

Blood samples with anticoagulant (EDTA) and without anticoagulant were collected via jugular venipuncture on days $-4,+3,+7$ and +14 . The blood samples without anticoagulant were transported to the laboratory on the farm to be centrifuged ( $3000 \mathrm{rpm}$, $10 \mathrm{~min})$. The resultant sera were stored at $-20{ }^{\circ} \mathrm{C}$ until their analysis. Samples with EDTA were processed on sampling day. Erythrocyte count, total leukocyte count, platelet count, hematimetric indices, and hematocrit percentage were obtained by using a veterinary blood counter (Model BC2800, Mindray Medical International Limited, Shenzhen, China). The hematocrit percentage and platelet count were also checked through a manual microhematocrit technique and microscopy visualization (Giemsa staining), respectively.

Serum biochemical parameters were estimated with a standard assay kit (Wiener Laboratories, Rosario, Argentina) and processed using a clinical chemistry analyzer (Mindray BS300, Shenzhen, China). Urease method, Jaffe's kinetic method, DGKC optimized kinetic method, IFCC kinetic method and DPD method were used to measure urea, creatinine, alkaline phosphatase, aspartate aminotransferase/gamma-glutamyl transpeptidase, and total bilirubin concentrations, respectively. Kidney function was monitored by means of urea and creatinine concentrations whereas liver function was assessed through serum alkaline phosphatase, aspartate aminotransferase, gamma-glutamyl transpeptidase, and total bilirubin concentrations. 
A completely randomized design was used. The data were analyzed using a mixed model with repeated measures over time with the Statistical Analysis System (SAS) statistical software (9.1). The fixed variables were group (1X vs. $2 X$ vs. $3 X$ vs. $1 X$ ext. vs. CTL), time (day -4 vs. +3 vs. +7 vs. +14 ) and their interaction (group-by-time). The animal within each treatment was the random variable. SLICE option of SAS was used to detect means when differences were significant. Significance was established as $p<0.05$ for the main effects and for their interaction.

\section{Results and Discussion}

Unusual behaviour such as depression, ataxia or prostration was not reported as a potential sign of toxicity associated with ketoprofen doses $(1 X, 2 X, 3 X)$ and treatment scheme (1X ext.) throughout this study. No local inflammation or pain was observed at the injection site.

The main evaluated blood components are presented in Table 1 . There were no time interactions or differences in hematocrit percentage, erythrocyte count, total leukocyte count and platelet count among the groups. The obtained values were within a normal range and no treatment-driven changes were reported. Hematimetric indices and hemoglobin concentration were similar in all the groups without group-by-time interactions $(p>0.1)$. Other authors observed thrombocytopenia after ketoprofen use in humans and dogs as a result of lactate dehydrogenase reduction in platelets is reduced $[18,19]$. However, the platelet counts reported in this study were within a normal range indicating that hematological parameters were not altered by the evaluated ketoprofen doses and treatment scheme.

Table 1. Least squares means for hematocrit percentage and erythrocyte, leukocyte and platelet counts in different groups treated with ketoprofen or sterile saline solution.

\begin{tabular}{|c|c|c|c|c|c|c|c|c|c|}
\hline \multirow{2}{*}{ Day } & \multicolumn{5}{|c|}{ Group (Least Squares Means) } & \multicolumn{4}{|c|}{$p$ Value } \\
\hline & $1 X$ & $2 X$ & $3 X$ & 1X ext. & CTL & SEM & Day & Group & Day by Group \\
\hline \multicolumn{10}{|c|}{ Hemotocrit (normal range $33-50 \%$ ) } \\
\hline-4 & 35.3 & 33.4 & 35.4 & 34.5 & 37.1 & 0.9 & $<0.001$ & 0.1919 & 0.4499 \\
\hline 3 & 31.5 & 32.4 & 33 & 31.4 & 33.9 & & & & \\
\hline 7 & 32.1 & 32.1 & 32.4 & 31.9 & 34.1 & & & & \\
\hline 14 & 32.9 & 31.8 & 34.1 & 34.1 & 34.9 & & & & \\
\hline \multicolumn{10}{|c|}{ Erythrocytes (normal range 5-8 million $/ \mathrm{mm}^{3}$ ) } \\
\hline-4 & 6.2 & 6 & 6.4 & 6.4 & 6.5 & 0.17 & $<0.001$ & 0.1228 & 0.4675 \\
\hline 3 & 5.6 & 5.7 & 6 & 5.9 & 6 & & & & \\
\hline 7 & 5.9 & 5.9 & 6 & 6 & 6.3 & & & & \\
\hline 14 & 5.7 & 5.5 & 5.9 & 6.3 & 6.1 & & & & \\
\hline \multicolumn{10}{|c|}{ Leukocytes (normal range 10-22 miles $/ \mathrm{mm}^{3}$ ) } \\
\hline-4 & 14.9 & 13.9 & 17.5 & 16.8 & 18.9 & 1.2 & $<0.001$ & 0.2059 & 0.3308 \\
\hline 3 & 14.6 & 13.3 & 21.3 & 15.7 & 15.8 & & & & \\
\hline 7 & 13 & 12.2 & 18.4 & 15.6 & 14.5 & & & & \\
\hline 14 & 11.7 & 12.4 & 13.4 & 14 & 12.4 & & & & \\
\hline \multicolumn{10}{|c|}{ Platelets (normal range $200-800$ miles $/ \mathrm{mm}^{3}$ ) } \\
\hline-4 & 475 & 443 & 435 & 455 & 411 & 4.5 & 0.006 & 0.8921 & 0.9234 \\
\hline 3 & 453 & 487 & 461 & 499 & 430 & & & & \\
\hline 7 & 429 & 404 & 398 & 457 & 369 & & & & \\
\hline 14 & 415 & 371 & 428 & 393 & 400 & & & & \\
\hline
\end{tabular}

Group 1X (3 mg/kg ketoprofen, $1 \mathrm{~mL} / 33 \mathrm{~kg}$. BW, $n=8)$; Group 2X (6 mg $/ \mathrm{kg}$. de ketoprofen, $2 \mathrm{~mL} / 33 \mathrm{~kg}$. BW, $n=8) ; \mathrm{Group} \mathrm{3X} \mathrm{(9} \mathrm{mg/kg.}$ ketoprofen, $3 \mathrm{~mL} / 33 \mathrm{~kg}$. BW, $n=8)$, Group $1 \mathrm{X}$-ext $(3 \mathrm{mg} / \mathrm{kg}$ ketoprofen, $1 \mathrm{~mL} / 33 \mathrm{~kg}$. BW for 3 consecutive days with a $24 \mathrm{~h}$ interval, $n=8)$ and Control Group (sterile saline solution $1 \mathrm{~mL} / 33 \mathrm{~kg}$. BW, $n=8$ ). Day -4 (4 days before treatment); day 0 (treatment day for group $1 \mathrm{X}$, $2 X, 3 X$ and last dose in the extended group), day +3 ( 3 days after treatment), day +7 ( 7 days after treatment) and day +14 (14 days after treatment). SEM: standard error of the mean. 
Liver function assessed through serum concentrations of different enzymes and bilirubin is shown in Table 2. All samplings indicated no changes due to ketoprofen administration. The mean values of alkaline phosphatase were above the normal range at the beginning of the treatment. Although its post-treatment values remained high, they were kept barely above the normal range. This enzyme is used as a marker of cholestasis in most animals [20]. Even though it is particularly concentrated in the hepatocellular cytoplasm, it is present in different body tissues. Thus, its activity should be considered together with other physiological factors such as age, nutritional status and heat stress [20-22]. In this study, no alkaline phosphatase between-group variations or group-by-day interactions were reported, which indicates that its concentrations were not increased after ketoprofen use.

Table 2. Least squares means for alkaline phosphatase, aspartate aminotransferase, gamma-glutamyl transpeptidase, total bilirubin concentrations in different groups treated with ketoprofen or sterile saline solution.

\begin{tabular}{|c|c|c|c|c|c|c|c|c|c|}
\hline \multirow{2}{*}{ Day } & \multicolumn{5}{|c|}{ Group (Least Squares Means) } & \multicolumn{4}{|c|}{$p$ Value } \\
\hline & 1X & $2 X$ & $3 X$ & 1X ext. & CTL & SEM & Day & Group & Day by Group \\
\hline \multicolumn{10}{|c|}{ Alkaline phosphatase (normal range 118-395 IU/L) } \\
\hline-4 & 594.6 & 526.1 & 506.9 & 518.3 & 524.2 & 32 & $<0.001$ & 0.43 & 0.89 \\
\hline+3 & 429.8 & 381.8 & 366.8 & 379.8 & 410.5 & & & & \\
\hline+7 & 418.6 & 370 & 343.5 & 379.6 & 416 & & & & \\
\hline+14 & 465.8 & 422.9 & 407.6 & 449.1 & 463.2 & & & & \\
\hline \multicolumn{10}{|c|}{ Aspartate aminotransferase (normal range 9-113 IU /L) } \\
\hline-4 & 30.0 & 33.4 & 31.8 & 27.8 & 31.4 & 16 & 0.06 & 0.36 & 0.67 \\
\hline+3 & 29.0 & 28.5 & 90.2 & 30.4 & 28.9 & & & & \\
\hline+7 & 32.4 & 32.6 & 42.4 & 29 & 30.9 & & & & \\
\hline+14 & 51.9 & 40.8 & 58.3 & 57.4 & 69.1 & & & & \\
\hline \multicolumn{10}{|c|}{ Gamma glutamyl transpeptidase (normal range 10-60 IU/L) } \\
\hline-4 & 34.6 & 31.8 & 21.6 & 28.6 & 34.1 & 3.7 & $<0.001$ & 0.083 & 0.89 \\
\hline+3 & 32.1 & 28.4 & 19.5 & 27.9 & 33.4 & & & & \\
\hline+7 & 33.3 & 31 & 19.9 & 28.6 & 33.5 & & & & \\
\hline+14 & 40.1 & 36 & 28.4 & 36.5 & 37.9 & & & & \\
\hline \multicolumn{10}{|c|}{ Total bilirubin (normal range $0.1-1 \mathrm{mg} / 100 \mathrm{~mL}$ ) } \\
\hline-4 & 0.16 & 0.27 & 0.19 & 0.16 & 0.19 & 0.06 & 0.002 & 0.18 & 0.33 \\
\hline+3 & 0.42 & 0.29 & 0.46 & 0.28 & 0.23 & & & & \\
\hline+7 & 0.28 & 0.28 & 0.43 & 0.21 & 0.29 & & & & \\
\hline+14 & 0.32 & 0.24 & 0.29 & 0.27 & 0.29 & & & & \\
\hline
\end{tabular}

Group 1X (3 mg/kg ketoprofen, $1 \mathrm{~mL} / 33 \mathrm{~kg}$. BW, $n=8)$; Group $2 \mathrm{X}(6 \mathrm{mg} / \mathrm{kg}$. de ketoprofen, $2 \mathrm{~mL} / 33 \mathrm{~kg}$. BW, $n=8)$; Group 3X $(9 \mathrm{mg} / \mathrm{kg}$. ketoprofen, $3 \mathrm{~mL} / 33 \mathrm{~kg}$. BW, $n=8)$, Group $1 \mathrm{X}$-ext $(3 \mathrm{mg} / \mathrm{kg}$ ketoprofen, $1 \mathrm{~mL} / 33 \mathrm{~kg}$. BW for 3 consecutive days with a 24-h interval, $n=8)$ and Control Group (sterile saline solution $1 \mathrm{~mL} / 33 \mathrm{~kg}$. BW, $n=8$ ). Day -4 (4 days before treatment); day 0 (treatment day for group $1 X$, $2 \mathrm{X}, 3 \mathrm{X}$ and last dose in the extended group), day +3 ( 3 days after treatment), day +7 ( 7 days after treatment) and day +14 ( 14 days after treatment). IU/L: international units per litre. SEM: standard error of the mean.

Moreover, aspartate aminotransferase and gamma-glutamyl transpeptidase concentrations were within a normal range without changes due to treatment. Aspartate aminotransferase is found in the mitochondria of liver cells whereas gamma-glutamyl transpeptidase is present in their cytoplasm [20]. The latter is also present in various body tissues and plays an important role in antioxidant mechanisms [23]. Consequently, its activity is also affected by oxidative stimuli in several species, including pigs [24]. Total bilirubin count is the sum of direct and indirect bilirubin. Indirect or non-conjugated bilirubin is pre-hepatic and increases when hemolysis occurs. Direct or conjugated bilirubin is a marker of cholestasis [20]. In this study, the total bilirubin concentration indicated no liver damage or intravascular hemolysis in this study. Mean values were within a normal range showing no statistically significant differences related to the treatment. Combined liver markers (alkaline phosphate, aspartate aminotransferase, gamma-glutamyl transpeptidase, and total bilirubin) showed normal liver function regardless of the dose and treatment scheme applied. 
Kidney function evaluated according to urea and creatinine concentrations are shown in Table 3. All samplings in this study showed no related-to-treatment differences. When kidney failure occurs, both concentrations are above the normal range [25,26]. All samplings in this study showed no related-to-treatment differences. Therefore, they were indicative of preserved kidney function after treatment.

Table 3. Least squares means for urea and creatinine concentrations in different groups treated with ketoprofen or sterile saline solution.

\begin{tabular}{|c|c|c|c|c|c|c|c|c|c|}
\hline \multirow{2}{*}{ Day } & \multicolumn{5}{|c|}{ Group (Least Squares Means) } & \multicolumn{4}{|c|}{$p$ Value } \\
\hline & $1 X$ & $2 X$ & $3 X$ & 1X ext. & CTL & SEM & Day & Group & Day by Group \\
\hline \multicolumn{10}{|c|}{ Urea (normal range $21-64$ mg\%) } \\
\hline-4 & 17.9 & 18.4 & 16.8 & 15.8 & 14.4 & $1.77^{\circ}$ & $<0.001$ & 0.426 & 0.471 \\
\hline+3 & 14.4 & 18.9 & 14.1 & 15.0 & 14.8 & & & & \\
\hline+7 & 20.1 & 19.5 & 17.3 & 18.4 & 19.0 & & & & \\
\hline+14 & 25.3 & 27.4 & 23.4 & 27.1 & 23.4 & & & & \\
\hline \multicolumn{10}{|c|}{ Creatinine (normal range 1-2.7 mg\%) } \\
\hline-4 & 1.0 & 1.0 & 1.0 & 1.0 & 1.1 & 0.03 & $<0.001$ & 0.504 & 0.370 \\
\hline+3 & 0.9 & 1.0 & 1.0 & 0.9 & 1.0 & & & & \\
\hline+7 & 1.0 & 1.0 & 1.0 & 0.9 & 1.0 & & & & \\
\hline+14 & 1.1 & 1.1 & 1.1 & 1.1 & 1.1 & & & & \\
\hline
\end{tabular}

Group 1X (3 mg/kg ketoprofen, $1 \mathrm{~mL} / 33 \mathrm{~kg}$. BW, $n=8)$; Group $2 \mathrm{X}(6 \mathrm{mg} / \mathrm{kg}$. de ketoprofen, $2 \mathrm{~mL} / 33 \mathrm{~kg}$. BW, $n=8)$; Group 3X (9 mg $/ \mathrm{kg}$. ketoprofen, $3 \mathrm{~mL} / 33 \mathrm{~kg}$. BW, $n=8)$, Group 1X-ext $(3 \mathrm{mg} / \mathrm{kg}$ ketoprofen, $1 \mathrm{~mL} / 33 \mathrm{~kg}$. BW for 3 consecutive days with a 24-h interval, $n=8)$ and Control Group (sterile saline solution $1 \mathrm{~mL} / 33 \mathrm{~kg}$. BW, $n=8)$. Day -4 (4 days before treatment); day 0 (treatment day for group $1 \mathrm{X}$, $2 \mathrm{X}, 3 \mathrm{X}$ and last dose in the extended group), day +3 ( 3 days after treatment), day +7 ( 7 days after treatment) and day +14 ( 14 days after treatment). SEM: standard error of the mean.

\section{Conclusions}

Ketoprofen administered intramuscularly in pigs at doses of 3,6 and $9 \mathrm{mg} / \mathrm{kg}$ (groups $1 \mathrm{X}, 2 \mathrm{X}$, and $3 \mathrm{X}$, respectively) did not produce any changes in hematological, hepatic, and renal parameters. Furthermore, these parameters remained normal when ketoprofen was consecutively administered for three days at a dose of $3 \mathrm{mg} / \mathrm{kg}$ bodyweight. The present study demonstrated that the use of ketoprofen at a higher dose than that established by the manufacturer's laboratory and/or at repeated doses does not induce alterations in the investigated parameters.

Author Contributions: Conceptualization, L.E.F. and J.F.R.; Data curation, S.J.R.; Formal analysis, L.E.F., S.J.R. and J.F.R.; Funding acquisition, S.J.R.; Investigation, L.E.F., S.J.R., J.F.R. and J.M.; Methodology, L.E.F., S.J.R., J.F.R. and J.M.; Project administration, L.E.F; Resources, L.E.F., J.M. and A.H.H.M.; Validation, L.E.F. and A.H.H.M.; Visualization, A.H.H.M.; Writing—original draft, L.E.F. and J.F.R.; Writing — review \& editing, J.M. and A.H.H.M. All authors have read and agreed to the published version of the manuscript.

Funding: This study was supported by a research grant from the National Program of Incentives to Teaching and Research, Secretary of University Policies, Ministry of Education of Argentina (Grant No. V257, School of Veterinary Sciences, National University of La Plata). The sponsor had no involvement in the study design, collection, analysis, or interpretation of the data presented in this paper.

Institutional Review Board Statement: The study was conducted according to the guidelines of the Institutional Animal Care and Use Committee (CICUAL, for its Spanish acronym), Faculty of Veterinary Sciences, National University of La Plata, Argentina (Protocol No 107-1-20P).

Data Availability Statement: The raw data regarding this article is available upon request to the corresponding author.

Acknowledgments: We are grateful to the owners of the farm Granja Don Darío who kindly collaborated with us in carrying out this study. 
Conflicts of Interest: S.J.R. and M.J. works for a company that produces NSAID and kindly provided the drug used in this investigation. The company had no involvement in the study design, collection, or analysis of the data presented in this paper. The authors declare that there are no additional conflict of interest.

\section{References}

1. Jiménez, T.M.; Papich, M.G. Prostaglandinas y antiinflamatorios no esteroideos. In Farmacología y Terapéutica Veterinaria; Botana, L.M., Landoni, F., Jiménez, T.M., Eds.; McGraw Hil-Interamericana: Madri, Spain, 2002; pp. 350-370.

2. Heo, S.K.; Cho, J.; Cheon, J.W.; Choi, M.K.; Im, D.S.; Kim, J.J.; Choi, Y.G.; Jeon, D.Y.; Chung, S.J.; Shim, C.K.; et al. Pharmacokinetics and pharmacodynamics of ketoprofen plasters. Biopharm. Drug Dispos. 2008, 29, 37-44. [CrossRef]

3. Mustonen, K.; Niemi, A.; Raekallio, M.; Heinonen, M.; Peltoniemi, O.A.; Palviainen, M.; Siven, M.; Peltoniemi, M.; Vainio, O. Enantiospecific ketoprofen concentrations in plasma after oral and intramuscular administration in growing pigs. Acta Vet. Scand. 2012, 54, 55. [CrossRef]

4. Meade, E.A.; Smith, W.L.; DeWitt, D.L. Differential inhibition of prostaglandin endoperoxide synthase (cyclooxygenase) isozymes by aspirin and other non-steroidal anti-inflammatory drugs. J. Biol. Chem. 1993, 268, 6610-6614. [CrossRef]

5. Lees, P.; Landoni, M.F.; Ciraudel, J.; Toutain, P.L. Pharmacodynamics and pharmacokinetics of nonsteroidal anti-inflammatory drugs in species of veterinary interest. J. Vet. Pharmacol. Ther. 2004, 27, 479-490. [CrossRef]

6. Singh, R.D.; Devi, S.; Gondaliya, S.R.; Bhavsar, S.K.; Thaker, A.M. Safety of ketoprofen in cow calves following repeated intravenous administration. Vet. World 2009, 2, 105-107.

7. Brink, P.; DeGraves, F.; Ravis, W.R.; Johansen, D.; Campbell, J.D.; Duran, S.H. Stereospecific pharmacokinetics of free and protein-bound ketoprofen in serum and synovial fluid of horses after intravenous and intramuscular administration. Am. J. Vet. Res. 1998, 59, 739-743. [PubMed]

8. Raekallio, M.R.; Mustonen, K.M.; Heinonen, M.L.; Peltoniemi, O.A.T.; Säkkinen, M.S.; Peltoniemi, S.M.; Honkavaara, J.M.; Vainio, O.M. Evaluation of bioequivalence after oral, intramuscular, and intravenous administration of racemic ketoprofen in pigs. Am. J. Vet. Res. 2008, 69, 108-113. [CrossRef] [PubMed]

9. Fosse, T.K.; Toutain, P.L.; Spadavecchia, C.; Haga, H.A.; Horsberg, T.E.; Ranheim, B. Ketoprofen in piglets: Enantioselective pharmacokinetics, pharmacodynamics and PK/PD modelling. J. Vet. Pharmacol. Ther. 2011, 34, 338-349. [CrossRef]

10. Tomic, Z.; Milijasevic, B.; Sabo, A.; Dusan, L.; Jakovljevic, V.; Mikov, M.; Majda, S.; Vasovic, V. Diclofenac and ketoprofen liver toxicity in rat. Eur. J. Drug Metab. Pharmacokinet. 2008, 33, 253-260. [CrossRef] [PubMed]

11. Swinkels, J.M.; Pijpers, A.; Vernooy, J.C.M.; Van Nes, A.; Verheijden, J.H.M. Effects of ketoprofen and flunixin in pigs experimentally infected with Actinobacillus pleuropneumoniae. J. Vet. Pharmacol. Ther. 1994, 17, 299-303. [CrossRef] [PubMed]

12. Salichs, M.; Sabaté, D.; Ciervo, O.; Homedes, J. Comparison of the antipyretic efficacy of ketoprofen, acetylsalicylic acid, and paracetamol, orally administered to swine. J. Vet. Pharmacol. Ther. 2012, 35, 198-201. [CrossRef] [PubMed]

13. Wyns, H.; Meyer, E.; Plessers, E.; Watteyn, A.; van Bergen, T.; Schauvliege, S.; De Baere, S.; Devreese, M.; De Backer, P.; Croubels, S. Modulation by gamithromycin and ketoprofen of in vitro and in vivo porcine lipopolysaccharide-induced inflammation. Vet. Immunol. Immunopathol. 2015, 168, 211-222. [CrossRef] [PubMed]

14. Reynolds, K.; Johnson, R.; Brown, J.; Friendship, R.; O'Sullivan, T.L. Assessing Pain Control Efficacy of Meloxicam and Ketoprofen When Compounded with Iron Dextran in Nursing Piglets Using A Navigation Chute. Animals 2020, 10, 1237. [CrossRef]

15. Homedes, J.; Salichs, M.; Sabaté, D.; Sust, M.; Fabre, R. Effect of ketoprofen on pre-weaning piglet mortality on commercial farms. Vet. J. 2014, 201, 435-437. [CrossRef] [PubMed]

16. Viitasaari, E.; Hänninen, L.; Heinonen, M.; Raekallio, M.; Orro, T.; Peltoniemi, O.; Valros, A. Effects of post-partum administration of ketoprofen on sow health and piglet growth. Vet. J. 2013, 198, 153-157. [CrossRef]

17. Viscardi, A.V.; Turner, P.V. Use of Meloxicam or Ketoprofen for Piglet Pain Control Following Surgical Castration. Front. Vet. Sci. 2018, 5, 299. [CrossRef]

18. Gaál, T.; Halmay, D.; Kocsis, R.; Abonyi-Tóth, Z. Evaluation of the effect of ketoprofen and carprofen on platelet function in dogs studied by PFA-100 point-of-care analyser. Acta Vet. Hung. 2007, 55, 287-294. [CrossRef]

19. Razi, M.T.; Javed, I.; Choudry, M.Z.; Khan, M.T.; Mukhtar, N. Effect of ketoprofen on lactic dehydrogenase from human platelets. Adv. Clin. Exp. Med. 2014, 23, 377-380. [CrossRef]

20. Kaneko, J.J.; Harvey, J.W.; Bruss, M. Clinical Biochemistry of Domestic Animals, 5th ed.; Academic Press: San Diego, CA, USA, 1997; ISBN 9780123963055.

21. Van Riet, M.M.J.; Millet, S.; Nalon, E.; Langendries, K.C.M.; Cools, A.; Ampe, B.; Du Laing, G.; Tuyttens, F.A.M.; Maes, D.; Janssens, G.P.J. Fluctuation of potential zinc status biomarkers throughout a reproductive cycle of primiparous and multiparous sows. Br. J. Nutr. 2015, 114, 544-552. [CrossRef] [PubMed]

22. Mendoza, S.M.; Boyd, R.D.; Ferket, P.R.; van Heugten, E. Effects of dietary supplementation of the osmolyte betaine on growing pig performance and serological and hematological indices during thermoneutral and heat-stressed conditions. J. Anim. Sci. 2017, 95, 5040-5053. [CrossRef]

23. Bachhawat, A.K.; Yadav, S. The glutathione cycle: Glutathione metabolism beyond the $\gamma$-glutamyl cycle. IUBMB Life 2018, 70, 585-592. [CrossRef] [PubMed] 
24. Chikhi, N.; Holic, N.; Guellaen, G.; Laperche, Y. Gamma-glutamyl transpeptidase gene organization and expression: A comparative analysis in rat, mouse, pig and human species. Comp. Biochem. Physiol. B Biochem. Mol. Biol. 1999, 122, 367-380. [CrossRef]

25. Misra, S.; Gordon, J.D.; Fu, A.A.; Glockner, J.F.; Chade, A.R.; Mandrekar, J.; Lerman, L.; Mukhopadhyay, D. The Porcine Remnant Kidney Model of Chronic Renal Insufficiency. J. Surg. Res. 2006, 135, 370-379. [CrossRef] [PubMed]

26. Huijuan, M.; Xiaoyun, W.; Xumin, Y.; Hengjin, W.; Xia, S. Effect of continuous bioartificial kidney therapy on porcine multiple organ dysfunction syndrome with acute renal failure. ASAIO J. 2007, 53, 329-334. [CrossRef] [PubMed] 